\title{
Effect of Multimedia Lesson With Blended Learning for Grade 4 Students
}

\author{
Tiamyod Pasawano* \\ Faculty of Technical Education \\ Rajamangala University of Technology Thanyaburi \\ Thanyaburi, Pathum Thani 12110, Thailand \\ *tiamyod@rmutt.ac.th
}

\begin{abstract}
The purposes of this research were; 1) created the blended learning lesson plan for Grade 4 students, 2) finding out the efficiency of the multimedia lesson, 3 ) compare the pretest and posttest of learning achievement result with blended learning and 4) finding out the effective index of the student's learning. The samples did were 30 students in Innovation Demonstration School of Rajamangala University of Technology Thanyaburi (RMUTT), Pathum Thani, Thailand who studying in the subject of social study religion and culture in the second term of the 2019 academic year by using the simple random sampling with cast lots method. The instruments used in this research are the Blended learning lesson, learning outcome test. This research is the quasi-experiment research using the pretest-posttest one group design. The data analyses were E1/E2, mean, standard deviation and t-test dependent. The result of research showed that; 1) the efficiency of the multimedia lesson by the $80 / 80$ standards had $83.95 / 85.57,2$ ) the learning achievement of students by using the blended learning lesson posttest higher than pretest had significantly 0.05 levels and 3 ) the effective index of this student's learning had 0.59 or 59 percent.
\end{abstract}

Keywords-blended learning, multimedia lesson, learning innovation

\section{INTRODUCTION}

The government's policy to accelerate the development of educational technology. By increasing the distribution of educational opportunities to people in urban and rural Thailand to learn throughout life. Accelerate the development of science and technology at all levels, both in quantity and quality. In response to the country's sustainable development, the Ministry of Information and Technology has prepared a Master Plan for Information Technology and Communications of the Year 2004-2006 and the Ministry of education the vision of information technology and communications, the $2004-2006$ that students, schools and educational bodies everywhere have access to and use of information and communications technology to be learning continuously. Life Management research career development. Quality of life the service has been thoroughly Quality and performance Leading to a society of knowledge and learning. Strategy and operating strategy; 4 is to use ICT to improve the quality of learners using ICT
Management Development. Management and educational services Production and development of personnel in the ICT and spreading ICT infrastructure for education, in addition, the aim of the basic education curriculum 2001 also requires the students to be creative, learning, love of reading. I love learning and research. There is universal knowledge; Knowingly changes and progress of science. And skills and capacity for learning. Communications and technology adaptive ways of thinking how to work with the harshest circumstances. The government has realized the importance of learning through the use of information and communications technology. Also known as E-learning is important and essential for developing countries to improve learning through technology integration, the development of E-learning a new one by the teaching blended with a variety of methods. With multiple media types. This is called the Blended Learning Blended Learning is a learning process $[1,2]$. The eclectic style of learning, whether it's learning happens in the classroom. Combined with learning outside the classroom to teach students who do not face each other or use a variety of learning resources [3]. Learning processes and activities arising from the strategy. Teaching a variety of forms. The goal is to help the students achieve the learning goals are important [4]. Teaching by means of blended learning that teachers can use to teach. Two or more in the course as instructors offer lessons through technology combined with traditional face to face teaching. But after that, instructor-led content articles hanging on the web. Then follow the activities of teaching using eLearning LMS systems with a computer lab. After a brief lesson by discussions with teachers in the classroom by blended learning (Blended Learning). Blending how many ways to use in teaching and learning for the students to learn (Teaching and Learning), as taught in the classroom with the teacher over the network (A Combination of Face-to-Face and Online learning) teaching methods should not be used to one way of making student learning. How many lives have to be combined?

Thus, teachers have an important role in choosing the medium of instruction. Creating a provocation and creating a learning environment that encourages students to show their knowledge and skills. And the students will have an interaction 
and collaboration between learners together produced a relationship between the students. Cause a team or group process. This will affect performance and a group working together.

The Ministry of Education has announced a policy to accelerate education reform. Based on the knowledge, moral awareness, a realization of the value of the sufficiency economy philosophy. Reconciliation peaceful democratic the development by virtue of the process, learn to associate the cooperation of the family, community, religious institutions and educational institutions to develop young people to become knowledgeable and well-being. The political, economic and social crisis which the country is facing now. Considering the all-around way, a way to relax the face Thailand should all contemplate joining forces to solve the problem, all parties agreed on reduction targets to meet each other halfway. To survive, security and prosperity of the country and ongoing sustainability. It's important to be in any way on the basis of merit, which is a pretty good thing to be the practice. Personal development by virtue of it is to help develop the nation into a complete human body, speech, and mind with education, it is vital to national development. Economic competitiveness in the era of globalization, it is up to education. Political development depends on education. Society was in decline I have to turn to the study. The development of education as a key condition of the development of the country. The coexistence of human society. One thing to avoid is not. Conflicting arguments disputing the opinions of those who believe that their comments are accurate, conflict and dispute settlement service. The man is sensitive to social organization in the early stages to the teachings of the prophet's religious majority is to take moral and morality is a refined mind to recognize the wrong oriented to make mistakes. The teachings of the prophet cause religious beliefs. Faith and culture of coexistence of humans. The beginnings of organized human society. To live together in peace among people of the same religion.

Systems nations in the world have invented to control human behavior. Is formed in the region between human beings themselves known. political regime the regime has invented many. The combination of political regimes together. And set up a new political regime. The current political regime has two main political dictatorships with a democratic political regime by democratic means, the regime, the regime of the country. This is the rule of the people, by the people and for the people, by the people of this does not mean, however, that only certain groups of people such as the poor, wealthy landowners, workers, farmers, or otherwise. It means people either nationally. It is difficult to do well, or any occupation These people shall have the right, duty, and responsibility. To govern the country together and equally well in a democracy. Hold the majority of those parties on the basis of national administration. At the same time the rights of minority people. It would be covered by the provisions of the law. Both parties see the side of it. Comments must be endowed with reason. And justified by the public in democratic governance. To understand the meaning of rights and freedoms that 3 people have this much right to the word in the sense of the dictionary of the Royal Institute Thailand provides definitions that. Is authorized to act on any. Freely The law has been approved by the word freedom is that people can choose to say, however, that the satisfaction of their duties and the last word refers to things that work should be done. Which varies according to their respective roles as parents are responsible for raising children. The children have expressed their gratitude to their parents. Students have studied these books and so on of issues such the research suggests that students in Grade 6, which is the youth who are interested. Curious Courage Heightened I want to use multimedia as learning a new one so that students do not learn in my classroom. The teachers are learning technology, combined with how many. With multiple media types, called Blended Learning into the curriculum for students Grade 4 at Innovation Demonstration School of Rajamangala University of Technology Thanyaburi (RMUTT), Pathum Thani, Thailand, to encourage students to learn on their own. democracy to come up with the students to become good adults in the future.

\section{THE PURPOSE OF STUDY}

- Created the blended learning lesson plan and Finding out the efficiency for Grade 4 students.

- Compare the pretest and posttest of learning achievement result with blended learning.

- Finding out the effective index of the student's learning

\section{SCOPE OF THE RESEARCH}

\section{A. Population and Demographics}

The population is students Grade 4 at Innovation Demonstration School of Rajamangala University of Technology Thanyaburi (RMUTT), Pathum Thani, Thailand 144 the 2 nd semester 2019 academic year.

Sample The students Grade 4 at Innovation Demonstration School of Rajamangala University of Technology Thanyaburi (RMUTT), Pathum Thani, Thailand, 30 people were selected by a specific (Purposive Random Sampling).

\section{B. The Variables Studied}

Independent variables include how students with learning Blended Learning with Multimedia-Grade 4. Variables such as Achievement with multimedia. Satisfaction of the students towards multimedia.

How Learning Blended Learning will require the students to learn the material in the classroom by teachers and Face - to - Face then to learn on their own by the Multimedia and return summaries in the classroom and the student achievement test. learning and a measure of satisfaction towards multimedia.

\section{Hypotheses}

After studying with multimedia stories rights and responsibilities by learning blended learning gives students a 
sense of democracy higher. Terminology Multimedia refers to a computer or electronic equipment unattended. The brain acts as a media assistant teacher in teaching students to learn the lesson content, including text, pictures, audio music.

The blended learning (Blended Learning) refers to teaching and learning, blended learning, E-learning by incorporating learning in regular classes. The learning content to the learner in the classroom by teachers and Face - to - Face then to learn on their own and return to the Multimedia Online Learning concludes in the classroom. The integration of Online Learning and Face-to-Face Meetings with the students to do a test to measure achievement and satisfaction of the students.

Promoting democracy means the content of the lessons. Rights and responsibilities. This will encourage the students to practice their rights and responsibilities. As a party determined society.

The experimental group represents students Grade 4 class in the 2nd semester 2019 academic year, a total of 30 people. Performance of multimedia means of achieving that aim CAI learning criteria $80 / 80$.

The first 80 refers to the average score of the students take the test as multimedia education accounted for 80 percent and 80 represents the average score of the students take the exam after studying multimedia for 80 percent.

\section{The Benefits Expected to be Received}

- A multimedia performance to promote democracy Grade 4 students.

- Students' learning achievement higher. Using a Multimedia Learning Blended Learning.

- A multimedia approach in bringing about more. To be applied to teaching in a similar manner.

\section{DETAILS EXPERIMENTAL}

Materials and Procedures in this research, the researchers used as a research tool. 1) Multimedia rights and obligations and 2) Test achievement. To produce the tools used in the research. In this study, the researcher has developed tools. The procedure is as follows.

\section{A. Multimedia Production}

In developing multimedia courseware for use in this study. A development stage multimedia [5] The first step to analyze the theoretical principles concerning the development stage. Study of learning social studies curriculum religion and culture then, define learning objectives and then write about their rights and duties. Then, the objective content to experts examined the contents of 3 , with the following experts is a qualified Master's degree in social studies class. Graduation for not less than 3 years old will be taught in social studies is not less than three years, taking into consideration the expert content validity. To check the authenticity or consider the objectives (IOC.) were then analyzed for. The criteria to be applied to up to 0.5 . Then, the objective content has updated the design of multimedia courseware by writing lesson storyboards and bring the storyboards. Content and technology professionals. Education or equivalent examination accuracy. The features of the technology specialist study, or related fields include a master 's degree in technology education or a related field. Graduation for not less than 3 years old will be taught in the technology, at least 3 years, then the multimedia courseware. Revised on the advice of experts. After creating multimedia then the multimedia courseware to provide expert evaluation of the content and media with a rate of 3 members. And finally brings multimedia to improve. On the advice of experts' multimedia and user groups.

\section{B. To Create a Test Achievement}

To develop tests for use in this study. The process of test development. Rights and duties by performing the following steps: First, define the purpose of the test. The design of the quiz is multiple choice option 4 , the structure of the test. Schedule and weight of the item. The design of the 40 exam questions put to the expert content. Using the same group of experts examined the contents of multimedia. To check the authenticity of the difficulty of content and coverage to improve the instructions. Then the expert evaluation of 3 checks the consistency of exam objectives (IOC.) has a value of 0.5 to apply to groups of 30 samples. Who are knowledgeable about this subject. The difficulty for the Split Haft is $30 \%$ to a value of 0.2 to 0.8 , and discrimination. Equal to 0.8 , then find the confidence. Screening test for the remaining 20 from the difficulty from 0.2 to 0.8 by select a value near 0.5 for a confidence value according to the formula KR - 20 (reference Kuder Richardson) confidence score of 0.80 or more and improve. The last step to prepare the test to be applied to the sample.

\section{The Efficiency}

This research was conducted in a multimedia performance. The process of finding effective E1/E2 has three stages.

- The efficiency of a single (1: 1) 80/80. The representatives of three people, including students with a GPA of high, medium and low 1 per person, the students learned by multimedia learning and Blended Learning, which is how it works is that the students learn the material in the classroom. teachers from the Face - to - Face then to learn on their own and return to the multimedia lessons in the classroom by the students to do the test. Posttest During and after learning the results to the E1/E2 threat criterion $80 / 80$.

- The efficiency of a small group of 6 people, including students with a GPA. of high, medium and low for 2 people, the students learned by multimedia learning and Blended Learning, which is how it works is that the students learn the content. in the classroom, teachers, and Face - to - Face then to learn on their own and return some of the multimedia in the classroom. After 
that, students take the exam after class. During and after learning the results to the E1/E2 threat criterion 80/80.

- The efficiency of a large group of 30 people with an average cumulative mixed class with multimedia lessons by learning Blended Learning, which is how it works is that the students learn the material in the classroom by teachers and Face - to - Face then to learn on their own and return some of multimedia in the classroom. Afterward, the students take the exam after class. Then the scores between classes and after the study to the E1 / E2 criteria 80/80.

\section{Data Collection}

In this research was conducted to collect data. The procedure is as follows:

- In the process of developing a model lesson. Researchers will collect interviews with experts and present the information collected and analyzed content validity. To check the authenticity or consider the objectives (IOC.) were then analyzed for. The criteria to be 0.5 to bring to a conclusion and choose the right model.

- Evaluation of lessons learned by experts in technology education for 3 people.

- Analyze the reliability of the test before and after learning. The deal is worth close to 0.5 for a confidence value according to the formula KR - 20 (reference Kuder Richardson) confidence score of 0.80 or more and improve.

- The experimental procedure Researchers collected data from Experiment 1, 1:1 to 2 times a small group of 6 people to determine the effectiveness of multimedia then update.

- In the experiment, researchers collected samples from 30 people to do the test before and after the learning. By learning with multimedia.

\section{E. Data Analysis}

In this study, Data analysis was conducted Following the results of tests to assess learning achievement. The analysis of difficulty discrimination and the conviction statistics Match paired T-test and then compare the difference of the average after-school and early learning with test T-test for Dependent with the software SPSS analyzed by average (. $\mathrm{x}$ ) and standard deviation (SD).

\section{RESULTS AND DISCUSSION}

To analyze all of the above. The researchers concluded that the findings of the objectives set. The following is.

- Performance Multimedia Lesson with Blended Learning to create and develop an effective $80 / 80$, is the efficiency rating is the percentage of the gaming activities equal to 83.95 (E1) and the percentage of the test scores. after the game was 85.57 (E2).

- Comparing the results before and after the test. The scores after learning through multimedia students were higher than the previous rate. Significant at 0.05 .

- The effectiveness index of this student's learning had 0.59 or 59 percent.

\section{DISCUSSION}

The study results of the Multimedia Lesson with Blended Learning of Students in Grade 4 at Innovation Demonstration School of Rajamangala University of Technology Thanyaburi (RMUTT), Pathum Thani, Thailand, with interesting issues discussed were the following.

Creating Multimedia to bring to trial samples. The creation and development of media through the work of expert evaluation. Professor of media and technology, education and professional content. Prior to the actual experiments with groups of students in three groups: a single center to determine the effectiveness of media, multimedia games. The hypothesis was determined to be an effective medium to $80 / 80$ by creating games to study. Talk to teachers, social studies lessons to meet the needs of the most active. The benefit of teaching. Students in Grade 4. In terms of measuring learning outcomes. The study was a test, measurement, and evaluation of learning. However, the test is considered by experts to be successful. An analysis of the difficulty and discrimination of all questions in the quiz. Scores before and after learning through media, multimedia games. For comparison, according to the hypothesis. The study found that the rate is higher than the previous statistically significant at the 0.05 level, according to the hypothesis. The reason that the lesson is part of the primary school Year 6 classes have ever been part of. You can learn a consistent and easy to understand even more.

\section{CONCLUSIONS}

The concept of blended learning means combined with several words. Including Blended Learning, Hybrid Learning, Integrated Learning, Multi-method Learning or Mixed Mode Learning and Flexible Learning. Multimedia performance must be designed using principles learned and developed through a systematic process. The multimedia designer should have knowledge of the principles in the design. In order to combine a variety of teaching theory to meet the individual differences of students.

\section{REFERENCES}

[1] S. Anderson, Managing universities in transition: Moving from traditional classroom-based delivery to blended and distance learning. United Kingdom: Open University, 2016.

[2] C.S. Askun, The relationship between students' level of effort and course perceptions in the blended learning environment. Indiana University, 2017 
[3] B. Bersin, General Characteristics of Distance Learning Universities, The Distance Learning Teaching Universities. New York: St.Martin's Press, Inc., 2014.

[4] B. Kajhonsilpa, Methodology in Education for learners. Bangkok: P.N.Publishing, 2014, pp.106-122.
[5] S.M. Alessi and S.R. Trollip, CBI: Methods and development. New Jersey: Prentice Hall, 1991. 